\title{
A certificação de desempenho ambiental de prédios: exigências usuais e novas atividades na gestão da construção
}

\author{
Green Building Certification: usual requirements and new \\ activities in construction management
}

\section{Rossana Piccoli \\ Andrea Parisi Kern \\ Marco Aurélio González \\ Ercília Hitomi Hirota}

\section{Resumo}

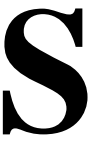

istemas de certificação ambiental de edifícios têm sido desenvolvidos, em diversos países, em decorrência dos significativos impactos ambientais causados pela construção civil. No Brasil já existem alguns empreendimentos certificados e outros em processo de certificação, ainda que seguindo sistemas estrangeiros. Em síntese, esses sistemas de certificação são compostos de critérios de avaliação que consideram diferentes aspectos ambientais, organizados em categorias. A certificação é concedida de

Rossana Piccoli Programa de Pós Graduação em

Engenharia Civil

Centro de Ciências Exatas e Tecnológicas Universidade do Vale do Rio dos Sinos

Avenida Unisinos, 950 São Leopoldo - RS - Brasil CEP 93022-000

Tel.: (51) 35908766 E-mail: ropthoz@terra.com.br

Andrea Parisi Kern Programa de Pós Graduação em Engenharia Civil

Centro de Ciências Exatas e Tecnológicas Universidade do Vale do Rio dos Sinos

E-mail: apkern@unisinos.br

Marco Aurélio González Programa de Pós Graduação em Engenharia Civil

Centro de Ciências Exatas e Tecnológicas Universidade do Vale do Rio dos Sinos E-mail: mgonzalez@unisinos.br

Ercília Hitomi Hirota Programa de Pós Graduação em Engenharia Civil

Centro de Ciências Exatas e Tecnológicas Universidade do Vale do Rio dos
Sinos

E-mail: ercilia@uel.br

Recebido em 08/09/2009 Aceito em 28/07/2010 acordo com o desempenho do edifício diante desses critérios. O presente artigo apresenta resultados de um estudo de caso no qual foram analisadas as peculiaridades na gestão da construção de edifícios candidatos a essa modalidade de certificação, identificando-se atividades usuais e novas atividades, quando comparadas à gestão da construção de edifícios, sem o interesse na certificação. Como estratégia de pesquisa realizou-se um estudo de caso durante a fase de produção de um prédio comercial que buscou a certificação de nível Gold do sistema norte-americano LEED. Os resultados apontam que o sistema de certificação exigiu atividades usualmente realizadas na fase de projeto, porém com um nível maior de envolvimento por parte dos projetistas. Na fase de produção, além de maiores exigências nas atividades tradicionalmente realizadas, identificaram-se novas atividades de gestão para a empresa construtora, assim como a necessidade de disponibilizar informações técnicas dos produtos por parte dos fornecedores.

Palavras-chave: Construção civil. Impactos ambientais. Certificação ambiental de edifícios.

\section{Abstract}

Green building certification systems have been developed in many countries, due to the significant environmental impacts caused by the construction industry. In Brazil, there are a few projects already certificated, and many others are still in process, even by foreign systems. These certification systems comprise a set of criteria which take into account different environmental aspects, organized in a set of categories. The certification is issued according to the evaluation of the building performance, based on those criteria. This paper presents the results of a case study, in which the authors analyzed the existence of significant differences in the project management process of a building for which it was intended to get a green building certification, compared with a usual one, with no interest in certification. The authors aimed to identify usual and new management activities. The research building that was aiming gold level of LEED certification. The results show that the certification system required more involvement of designers, in ordinary activities. In production phase, besides a stronger involvement of the building company, the authors identified new management tasks, as well as the need of more detailed technical information from the suppliers of the construction materials and components.

Keywords: Civil construction. Environmental impact. Green building certification. strategy adopted was a case study during the production phase of a commercial 


\section{Introdução}

A indústria da construção civil produz sérios impactos ambientais, seja pelo alto consumo de recursos naturais e de energia, seja pela grande quantidade de resíduos gerada. Aproximadamente $35 \%$ do volume total de recursos naturais empregados no setor produtivo é consumido pela construção civil (JOHN, 2000). De acordo com o Balanço Energético Nacional (BRASIL, 2008), os edifícios brasileiros consomem cerca de $45 \%$ do total da energia elétrica produzida. A produção mundial de cimento é responsável por $7 \%$ das emissões globais de $\mathrm{CO}_{2}$ para a atmosfera (PIERCE, 2002). Segundo Pinto (1999), os resíduos de construção e demolição constituem de $41 \%$ a $70 \%$ da massa dos resíduos sólidos urbanos. Além desses, Couto e Couto (2007) ainda citam os impactos sonoros e visuais, e a poluição do ar (poeira) causados na execução de obras.

Em contraponto, algumas iniciativas vêm sendo tomadas para reduzir os impactos ambientais da construção civil. Países como Estados Unidos, Canadá, Austrália, Japão, China (Hong Kong) e alguns europeus têm investido em sistemas de certificação de edifícios, com base em critérios e indicadores de desempenho ambiental. Segundo Silva (2003), o grande impulso ao desenvolvimento desses sistemas surgiu a partir da constatação de que, mesmo os países que acreditavam dominar os conceitos de projeto ecológico, não possuíam meios para verificar quão "verdes" eram de fato seus edifícios.

A maioria dos sistemas existentes funciona por adesão, com a intenção de que o próprio mercado impulsione a elevação do padrão ambiental, seja por comprometimento ambiental ou por questão de competitividade e diferenciação mercadológica (ZIMMERMANN et al., 2002). Por outro lado, segundo Silva (2007), em alguns países, a proposta de certificação "verde" das edificações deixou de ser meramente estratégia de mercado e passou a ser condição para a legalização do edifício. Por exemplo, desde 1992, a Dinamarca passou a exigir dos grandes edifícios comerciais o atendimento a um sistema de avaliação de energia. Esse sistema de avaliação é obrigatório, relativamente caro e bastante abrangente (CANTALAPIEDRA; BOSCH; LÓPEZ, 2006).

No Brasil, a certificação ambiental de prédios já é percebida pelos agentes do setor da construção civil, e o interesse pelo tema está se consolidando. O primeiro sistema brasileiro de certificação ambiental de edifícios para o setor da construção civil foi criado em 2007, o Referencial Técnico de Certificação: edifícios do setor de serviços, sistema Alta Qualidade Ambiental (AQUA), da Fundação
Vanzolini, baseado no sistema francês NF Bâtiments Tertiaires - Démarche HQE® (AULICINO, 2008; FUNDAÇÃO VANZOLINI, 2008).

Outras iniciativas identificadas consistem na criação, em 2003, do Programa Nacional de Eficiência Energética em Edificações - PROCEL EDIFICA, que visa incentivar a conservação e o uso eficiente dos recursos naturais (água, luz, ventilação, etc.) nas edificações, reduzindo os desperdícios e os impactos sobre o meio ambiente (BRASIL, 2009), e o Selo Azul da Caixa Econômica Federal, que certifica empreendimentos segundo 46 critérios (CAIXA ECONÔMICA FEDERAL, 2009).

No entanto, a aplicação dessas iniciativas ainda é incipiente, e a adoção de sistemas estrangeiros aumenta no país. Nesse contexto, destaca-se o sistema norte-americano Leadership in Energy and Environmental Design (LEED), que tem sido adaptado às edificações brasileiras.

O LEED é um sistema de classificação e certificação ambiental projetado para a indústria de construção americana, criado em 1996 pelo US Green Building Council (USGBC). Esta instituição, sem fins lucrativos, é financiada pelo National Institute of Standards and Technology (NIST) a partir da iniciativa de alguns agentes individuais, incluindo representantes do mercado de construção civil, órgãos governamentais e associações de classe (HERNANDES; DUARTE, 2007).

$\mathrm{Na}$ versão atual para novas construções (LEED$\mathrm{NC}$ ), os vários créditos são distribuídos em cinco categorias de impactos ambientais (sítios sustentáveis; uso eficiente de água; energia e atmosfera; materiais e recursos; e qualidade do ambiente interno) e mais cinco créditos são destinados à categoria de inovação e processo de projeto. Como referência aos princípios ambientais e de uso de energia, o LEED é baseado em normas de credibilidade reconhecida, definidas por entidades como a American Society of Heating, Refrigerating and Air-Conditioning Engineers (ASHRAE), a American Society for Testing and Materials (ASTM); a Environmental Protection Agency (EPA) e o Department of Energy (DOE) (BENINI et al., 2003).

No Brasil, o LEED tem sido utilizado para conferir o selo de "green building", já implementado por algumas empresas construtoras, especialmente em obras comerciais nos grandes centros urbanos. De acordo com os dados disponibilizados pelo USGBC (2006), existem cinco empreendimentos certificados no país e 123 empreendimentos registrados com intenção de certificação. 
Em síntese, a maioria dos sistemas de certificação ambiental utiliza listas de verificação que concedem créditos em função da aplicação de determinadas estratégias de projeto ou especificação de materiais e equipamentos (DEGANI; CARDOSO, 2002). Esses sistemas são compostos de determinado conjunto de critérios que respeitam diferentes categorias de aspectos ambientais e fatores de construção relevantes, sendo a certificação dos edifícios efetuada de acordo com seu desempenho diante desses critérios (COLE; LARSSON, 2002; PINHEIRO; SOARES, 2005).

A preocupação com critérios de desempenho na construção é uma tendência mundial, porém no Brasil ainda existe um longo caminho a ser percorrido. Por exemplo, toda a normalização técnica brasileira existente referente à construção civil é prescritiva, ou seja, tem a preocupação quanto à forma (meio) com que o produto deve ser construído, e não com o desempenho esperado do produto, ou sistema (BORGES; SABBATINI, 2008). Como exemplo podem ser citados os códigos de obras que especificam a espessura das paredes externas, o tamanho das aberturas, a altura dos prédios, etc.

Ao contrário, a abordagem de desempenho, fortemente presente nos sistemas de certificação ambiental, pode ser entendida como a prática de se pensar em termos de fins, e não de meios, tendo como foco o atendimento de diferentes requisitos que a construção deve adotar. Por esse viés, entende-se que o parâmetro de desempenho das paredes externas (utilizando o mesmo exemplo) não será alcançado levando-se em conta apenas sua espessura. Nesse contexto, em 2008, um importante passo foi dado pela Associação Brasileira de Normas Técnicas (ABNT, 2009) com a publicação da NBR 15575, sob o título geral de "Edifícios habitacionais de até cinco pavimentos: desempenho", a qual entrou em vigor em junho de 2010. O objetivo central dessa norma é atender às exigências dos usuários mediante a garantia de desempenho dos sistemas que compõem edifícios quanto a seu comportamento em uso, e não na prescrição de como os sistemas devem ser construídos.

Contudo, por mais que a preocupação com desempenho seja uma tendência mundial, a aplicação desse conceito na construção ainda depende de vários fatores, incluindo a formação e a capacitação dos profissionais (projetistas, gestores) e mão de obra, adequação da legislação e normas e adequação da cadeia de fornecedores.

A migração da abordagem prescritiva para a abordagem de desempenho é um desafio, pois exige mudança na forma como os projetistas concebem o produto, com a necessidade de conhecer o comportamento no uso das soluções de projeto (BORGES; SABATINI, 2008). Especialmente no Brasil, os projetistas não possuem formação, tampouco têm tradição em conceber os projetos utilizando a abordagem de desempenho. Para atingir esse objetivo, é necessária uma forte interação entre membros da equipe durante todo o processo de projeto, pois muitas soluções podem exigir um caráter multidisciplinar (HOPFE, 2009).

Além da abordagem de desempenho do produto, a maioria dos sistemas de certificação também faz exigências na fase de produção, visando diminuir impactos ambientais do canteiro de obras, tais como poeira, ruído, consumo de energia e gerenciamento de resíduos.

Nessa linha, em termos de gestão de resíduos de construção, há que se citar que em 10 de julho de 2001 foi promulgada a Lei Federal 10.257/01, que exige a adoção de políticas setoriais articuladas por parte dos municípios, com destaque à política de gestão dos resíduos sólidos, a qual originou a Resolução $n^{\circ}$ 307/02 do Conselho Nacional do Meio Ambiente (BRASIL, 2002). Entretanto, o que se constata é que a exigência e a fiscalização do cumprimento e da adequação a essa resolução até hoje não são efetivas. Como resultado, a postura inadequada de grande parte das empresas de construção civil (especialmente projetistas e construtoras) em relação ao impacto ambiental gerado decorrente de sua atividade expressa o reflexo da ausência de informações e do descomprometimento social.

Nesses quesitos, o baixo nível tecnológico com o qual o setor opera, o insuficiente treinamento dos operários, a falta de planejamento organizacional e social, a carência de educação ambiental, não só por parte dos operários, mas também dos profissionais e do setor empresarial, e a pouca informação a respeito da situação das condições ambientais e sociais em que a obra se realiza também podem ser considerados desafios para o setor (SILVA, 2007).

Este artigo tem como base uma dissertação de mestrado cuja motivação ocorreu principalmente pela oportunidade em participar de uma equipe de profissionais que atuou na fiscalização da execução da primeira obra de grande porte no Rio Grande do Sul que buscou o selo norte-americano de certificação ambiental LEED, no nível Gold (PICCOLI, 2009). O artigo tem como objetivo discutir as exigências e as novas atividades na gestão da construção que surgem em decorrência do objetivo de obter a certificação ambiental de edifícios. Cabe ressaltar que não está no escopo do 
trabalho analisar e discutir o sistema de certificação em si, tampouco avaliar o projeto do empreendimento em termos de eficiência e desempenho ambiental.

\section{Método de pesquisa}

A estratégia de pesquisa utilizada foi o estudo de caso, o qual teve duração de 13 meses, com início em abril de 2008. Nesse mês a obra já havia sido iniciada, e a pesquisadora participou de reuniões realizadas entre cliente, projetistas, construtor e fornecedores, durante a fase de execução da obra. Nessas reuniões eram discutidas questões de projeto, andamento da obra e atendimento aos requisitos do sistema de certificação ambiental.

As reuniões eram realizadas semanalmente, com a participação de representantes do proprietário, engenheiros, construtora, empresa de fiscalização e o profissional responsável pela certificação LEED. Além dessa reunião semanal, também era realizada uma reunião mensal, para apresentação dos relatórios de todas as atividades, tanto burocráticas quanto construtivas, e documentações para aprovações, envolvendo documentação para a Prefeitura e para a certificação LEED. Essas reuniões eram realizadas em inglês, em função de o proprietário ser norte-americano. Ocasionalmente foram realizadas reuniões extras, para resolver assuntos urgentes.

Ao todo, a pesquisadora participou de aproximadamente 50 reuniões semanais, 13 reuniões mensais e 10 reuniões extras, ocorridas no período de abril de 2008 a maio de 2009. Nas reuniões, adotou-se a observação participante, buscando registrar principalmente as atividades, as soluções e as dificuldades observadas durante o processo.

Também foram realizadas entrevistas informais com os envolvidos, especialmente projetistas, representantes da empresa construtora e da empresa fiscalizadora. A grande preocupação na realização do estudo foi diferenciar, entre as atividades realizadas pelos envolvidos, aquelas que não fazem parte do escopo dos profissionais, ou são exigidas de forma diferente, em empreendimentos tradicionais, que não buscam a certificação.

Além disso, analisaram-se os documentos da obra, tais como projetos, memoriais, contratos e, principalmente, os relatórios exigidos pelo sistema de certificação e atas das reuniões ocorridas no período.

\section{Descrição do empreendimento}

O empreendimento estudado consiste em um prédio comercial composto de um pavimento de subsolo e três pavimentos-tipo, divididos em dois blocos, separados por um espelho d'água, além de área para estacionamento e de ajardinamento. A construção tem duas fases. A primeira fase, objeto deste estudo, é constituída de subsolo, térreo, primeiro e segundo pavimentos, com área total de $7.326,92 \mathrm{~m}^{2}$. A segunda fase está prevista para ser construída em 2011 e consiste num prédio de iguais características.

Para a realização do projeto desse empreendimento realizou-se um concurso com a participação de vários projetistas, sendo critério de escolha o atendimento às especificações determinadas pelo sistema de certificação LEED. O projeto escolhido teve como premissas a racionalização construtiva e o máximo aproveitamento dos elementos arquitetônicos, visando a menor consumo de energia da edificação na fase pós-ocupação.

\section{Descrição da contratação dos profissionais do empreendimento}

A Figura 1 mostra a relação entre os principais profissionais contratados para a realização do empreendimento, considerando as fases de projeto e de produção. As setas indicam as relações contratuais.

Conforme se mostra na Figura 1, o empreendedor contratou o projeto arquitetônico, e o arquiteto responsável pelo projeto contratou os demais projetistas (cálculo estrutural, sistema de ar condicionado, instalações elétricas e hidrossanitárias, paisagismo, automação).

Para a execução da obra, o empreendedor contratou uma empresa construtora de grande porte (Construtora A), com sede em São Paulo, a qual afirmou ter conhecimento do sistema de certificação LEED, seus parâmetros, requisitos e demais exigências. Pelo contrato realizado, a empresa construtora ficou responsável pela contratação da mão de obra e dos fornecedores.

Contudo, após um ano de andamento da obra, o contrato foi cancelado tendo em vista a falta de comprometimento da Construtora A com a certificação da edificação. Outra empresa foi contratada (Construtora B) para a conclusão da obra, tendo como importante diferencial um profissional com conhecimento sobre certificação LEED para orientar e esclarecer as equipes de trabalhadores, bem como para produzir a documentação necessária, dentro das exigências e padrões da certificação escolhida. Outra referência importante é que a Construtora B tem sede em Porto Alegre, o que facilitou as relações com fornecedores e subempreiteiros locais. 


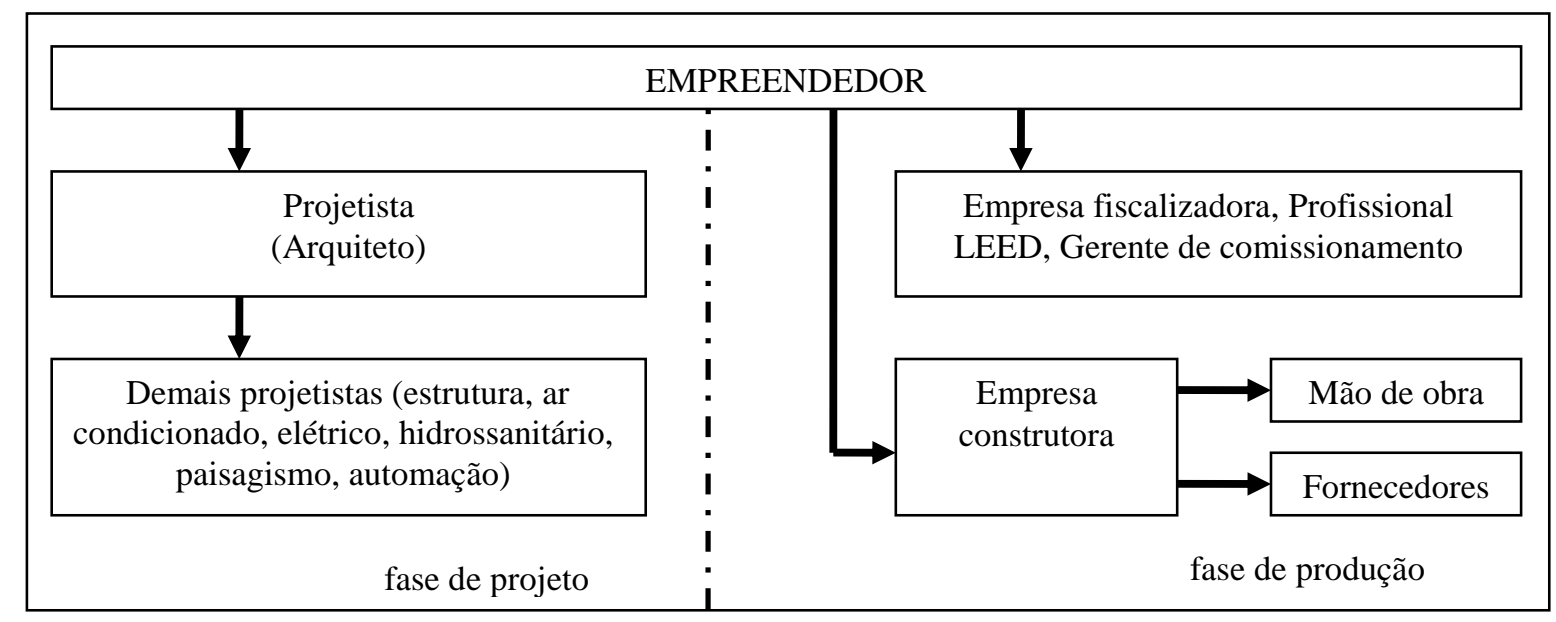

Figura 1 - Principais envolvidos nas fases de projeto e produção

Durante a fase de execução da obra, o empreendedor contratou também uma empresa fiscalizadora, que o representava junto à empresa construtora e aos projetistas, um profissional credenciado LEED, que auxiliou na elaboração dos documentos, e um gerente de comissionamento (exigência do LEED), para garantir a eficiência dos equipamentos relacionados à área de energia.

\section{Apresentação e análise dos resultados \\ Principais envolvidos e exigências da certificação}

A seguir, com base na realização do estudo de caso, descrevem-se as atividades realizadas pelos principais envolvidos em decorrência da certificação, identificadas como diferentes ou novas, em relação ao escopo tradicional na construção.

\section{Projetistas}

O envolvimento dos projetistas demonstrou ser o elemento mais importante de todo o processo, pois pode ser considerado o principal determinante para que o empreendimento atingisse as características de desempenho ambiental exigidas para a certificação. Conforme depoimentos colhidos, as atividades desenvolvidas nos projetos tiveram maior preocupação com o desempenho ambiental e exigiram soluções que atendessem aos requisitos específicos do sistema de certificação.

Como exemplo, podem ser citadas algumas soluções de projeto, tais como a opção por forros e vidros especiais, brises verticais e horizontais (para sombreamento nas fachadas), aberturas com vistas para o exterior e ventilação natural, para garantir o conforto acústico e térmico dentro dos padrões do sistema de certificação. Como estratégia de racionalização da energia foram adotados projetos de automação para o controle de equipamentos elétricos, ar condicionado e iluminação. No projeto paisagístico foram previstos um espelho d'água e vegetação de espécies nativas para sombreamento adequado, diminuindo as ilhas de calor, para atingir o controle do calor externo exigido para a certificação. A redução do consumo de água potável foi prevista com a utilização de água de reúso nos sanitários, sistema de refrigeração do arcondicionado e na rega de jardins, a partir da coleta e encaminhamento a uma estação de tratamento total do esgoto.

Uma atividade que exigiu muito esforço dos projetistas foi a elaboração do memorial descritivo. Conforme depoimento dos projetistas, essa prática foi significativamente diferente da que ocorre tradicionalmente na construção, na qual a exigência de detalhamento não é tão ampla. Devido à certificação, o memorial descritivo foi realizado com extensas e detalhadas especificações e definiçõos das características dos materiais e componentes, bem como do sistema construtivo e das formas de execução, tendo em vista os parâmetros de desempenhos determinados pelo sistema de certificação ambiental.

Como exemplo da abrangência do memorial descritivo, podem ser consideradas as especificações dos equipamentos para utilização na execução, em termos de ruído e consumo de energia (com comprovação de ensaios de simulação energética), a especificação e a medição do fluxo luminoso no prédio, e a especificação de vidros e esquadrias, que exigiram a realização de testes e simulações em laboratórios americanos quanto a refletância, estanqueidade e isolamento 
térmico (os quais foram realizados com base na norma ASHRAE 90.1/2004).

Outra exigência da certificação foi o uso de materiais regionais. Como na obra estudada o arquiteto contratado era de outro estado, ele teve de conhecer e especificar materiais da região da obra. Por exemplo, na pavimentação das áreas externas e internas, bem como para os tampos das pias dos sanitários, os projetistas especificaram a pedra basalto, amplamente encontrada na região. No projeto de paisagismo especificaram-se espécies nativas, bem como uma vegetação que exigisse menos manutenção e consumo de água.

\section{Empresas construtoras}

Como atividades realizadas pelas Construtoras A e B em decorrência da certificação, podem ser citadas a solicitação aos fornecedores de materiais de documentos que comprovassem a especificação dos materiais, já que as empresas construtoras eram responsáveis pela contratação dos fornecedores, e a gestão no canteiros de obras, tendo em vista a contratação também da mão de obra.

Essas atividades foram facilmente identificadas e relacionadas com exigências da certificação a partir dos problemas enfrentados pela falta de comprometimento com a certificação da Construtora A. A desconsideração da comprovação das especificações dos materiais gerou atrasos na aquisição de materiais e um clima muito tenso entre a Construtora A e o cliente, o que levou à substituição da construtora. Como exemplo de documentos que foram exigidos podem ser citados declaração ambiental, ficha técnica (composição química, reciclados) e regionalidade (distância do local de fornecimento à obra).

Em termos de gestão de canteiro, coube às construtoras a implementação de um sistema de gestão dos resíduos da obra, gerando documentação comprobatória do resíduo destinado a aterros (especificação do material, transportador e destino final) e o controle de poeira, ruídos e erosão. Essas atividades exigem treinamento da mão de obra e constante fiscalização.

\section{Fornecedores}

Os fornecedores tiveram uma participação singular no esforço de entregar produtos dentro dos padrões exigidos pelos projetistas e pelo empreendedor para garantir a certificação do empreendimento. Alguns tiveram um envolvimento mais intenso, pois foi necessário adaptar o produto às exigências do sistema de certificação. Por exemplo, a fornecedora de concreto modificou a composição do concreto da obra, substituindo $25 \%$ da areia natural por resíduo de britagem.

\section{Empresa fiscalizadora, Profissional LEED e Gerente de comissionamento}

Durante a execução da obra, a empresa fiscalizadora ficou responsável por documentar a obra por meio de relatórios descritivos e fotográficos, para a conferência da qualidade dos trabalhos e a conferência do uso dos materiais conforme especificações dos projetistas.

O profissional LEED pode ser considerado um agente obrigatório em empreendimentos a serem certificados por esse sistema. Na obra, esse profissional teve como atividades principais orientar as decisões, fornecer as informações essenciais sobre o processo de certificação e organizar a documentação exigida para envio ao USGBC. Vale ressaltar que a contratação desse profissional creditou um ponto para a certificação do empreendimento.

O gerente de comissionamento também foi um agente exigido pelo sistema de certificação. As principais atividades do gerente de comissionamento foram verificar e garantir que os sistemas relacionados à área de energia estivessem instalados, calibrados e com as características de desempenho conforme os requisitos de projeto e os documentos da construção, exigidos pelo sistema de certificação. Na obra estudada, os seguintes sistemas relacionados à energia foram comissionados: de aquecimento, ventilação, ar condicionado e refrigeração, iluminação, sistemas de água quente e sistema de automação predial.

\section{Dificuldades encontradas para 0 atendimento das categorias do sistema de certificação}

A seguir são descritas as principais dificuldades encontradas pelos envolvidos, tendo em vista a busca do atendimento aos requisitos da certificação, considerando as cinco categorias do LEED.

\section{Sítios sustentáveis}

Esta categoria exigiu um plano de prevenção da poluição nas atividades de construção, o que não é uma prática usual na construção civil (exceto por alguns itens, como o lava-rodas, cujo uso tem sido cada vez mais exigido em diferentes tipos de construção). A Construtora A encontrou dificuldades para elaborar e seguir o plano, tendo em vista que as equipes de trabalho o desconheciam e não foram orientadas adequadamente nesse sentido. 
Apesar de ter um maior conhecimento do processo de certificação, a dificuldade encontrada pela Construtora B foi no planejamento e ordenamento de atividades que levassem à redução de movimentação e exposição de solo. Verificações periódicas das medidas tomadas para a minimização da erosão foram necessárias, bem como a manutenção de diversos itens, como o lava-rodas, o lava-bica para caminhão de concreto, as proteções com material geotêxtil nas bocas de lobo, os anteparos junto aos pés de taludes e as lonas para proteção destes. Como se trata de um pré-requisito, o controle da erosão e sedimentação mereceu uma atenção especial por parte da empresa construtora, pois, segundo a análise do solo realizada, o terreno mostrou ser pouco permeável, o que contribuiu para que houvesse áreas alagadas e com escoamento lento em alguns pontos do terreno, principalmente em períodos de chuva.

\section{Uso eficiente da água}

Nesta categoria não houve dificuldades. De fato, não foi previsto pelo projeto recolhimento da água da chuva, mas o tratamento de todo o esgoto através de uma estação de tratamento de esgoto (ETE), onde $100 \%$ do esgoto produzido na edificação será tratado, e a água será reutilizada em vasos sanitários e regas de jardim, garantindo assim a pontuação na categoria.

\section{Energia e atmosfera}

Como o principal elemento da edificação é a fachada de concreto com vidros expostos, a maior dificuldade encontrada nessa categoria foi a análise dos vidros para comprovação da simulação energética da edificação. Como a Construtora A desconhecia as questões que envolviam a certificação, na compra dos vidros, essa análise não havia sido realizada, o que gerou atrasos na execução e colocou em risco a certificação que o empreendedor buscava.

No período em que a Construtora $\mathrm{B}$ assumiu a execução, foram realizados testes por laboratório credenciado no exterior, utilizando-se procedimentos de ensaio estabelecidos pelos procedimentos NFRC 100, NFRC 200 e NFRC 400 da National Fenestration Rating Council (www.nfrc.org), segundo os quais devem ser apresentados valores de $U$ factor (coeficiente de transmissão térmica do vão envidraçado) que dependem de três fatores fundamentais: as características técnicas dos vidros, a qualidade da caixilharia e o grau de proteção oferecido pelo sistema de sombreamento exterior. Esse conjunto de fatores deve reduzir as perdas térmicas do interior para o exterior, para que sejam criadas condições de conforto no interior, e deve controlar os ganhos de calor do exterior para o interior. Outra análise que foi realizada é do SHGC (Solar Heat Gain Coefficient - coeficiente de ganho de calor solar), que mede a fração de radiação solar incidente através de um vidro - quanto menor o coeficiente, menor o calor transmitido para o ambiente. Também se fez a análise dos vidros conforme exigências mandatórias da norma ASHRAE 90.1/2004, o que tornou o processo lento e oneroso, tanto para o empreendedor quanto para a construtora.

\section{Materiais e recursos}

Esta categoria concentra o maior número de créditos sob a responsabilidade da construtora no processo de certificação. Uma dificuldade das construtoras foi encontrar empresas que fizessem o reaproveitamento final de determinados resíduos que não possuem reutilização consagrada no mercado (tais como lã de rocha, lã de vidro e gesso). Outra tarefa difícil no processo foi encontrar produtos com conteúdo reciclado que apresentassem informações claras sobre o percentual de material reciclado incorporado ao processo de fabricação.

Grande parte dos produtos empregados na construção do empreendimento foi encontrada em um raio de $800 \mathrm{~km}$ do local da obra, como preconiza a certificação. A dificuldade, porém, foi planejar a especificação e as alternativas disponíveis com antecedência e de forma alinhada com o arquiteto, pois para o processo de certificação há necessidade de comprovação da origem dos materiais através da rastreabilidade de documentos. Nesse quesito, a falta de conhecimento e de comprometimento da Construtora A causou sérios problemas por ela não solicitar documentação adequada aos fornecedores.

A aquisição de madeira certificada foi outra questão que envolveu dedicação para ambas as construtoras. As maiores dificuldades encontradas foram a análise da documentação comprobatória (certificado emitido pelo FSC - Forest Stewardship Council) e a necessidade de fornecer orientações ao fornecedor para incluir o número do certificado na nota fiscal. Percebeu-se que esse processo de certificação ainda é muito pouco difundido no mercado regional da indústria madeireira, decorrendo desse fato a dificuldade de os fornecedores atenderem aos parâmetros de qualidade exigidos pelo sistema de certificação da obra. 


\section{Qualidade do ambiente interno}

A necessidade de se fazer um Plano de Qualidade Interna do Ar para a fase de produção pode ser considerada como uma novidade para a construção civil brasileira. Conscientizar os operários da construção a seguir o que está preconizado nesse plano foi a maior dificuldade relacionada a essa categoria. Atividades simples como limpeza do ambiente de trabalho ao final de cada atividade, colocação de lona plástica sobre o piso, minimização de poeira com o umedecimento do piso durante a varrição, uso de máscaras protetoras e luvas em atividades específicas tiveram de ser cuidadosa e continuamente inspecionadas, tendo em vista a falta de hábitos de organização, de limpeza e de segurança nos canteiros de obras convencionais.

O Plano de Qualidade do Ar Interno na fase de pré-ocupação também requereu atenção da Construtora B. Esse crédito oferece duas alternativas. Uma delas consiste na análise da qualidade do ar por laboratório, que foi descartada por ser ainda muito cara no Brasil e porque somente uma empresa de São Paulo realiza esse trabalho. A segunda alternativa consiste na realização da ventilação do ar no interior da edificação (flush out) após o término da construção e em momento anterior à ocupação da edificação. Essa atividade ocorre quando todos os equipamentos e acabamentos estão instalados e tem como objetivo remover resíduos ou poluições emitidas, minimizando os problemas da qualidade do ar interno resultantes do processo de construção. Trata-se de um processo pouco empregado, e sua dificuldade residiu no fato de se conciliar o final de obra ao cronograma e às atividades inerentes à entrega da obra, como reparos, acabamentos finais e arremates.

Outras dificuldades encontradas pela Construtora B nessa categoria foram contratar fornecedores que tivessem desenvolvido produtos com compostos orgânicos voláteis abaixo do limite exigido pelo sistema de certificação escolhido e encontrar materiais isentos de ureia-formaldeído em sua composição. Como exemplo, na fabricação das portas, a ureia-formaldeído é encontrada nas colas e resinas utilizadas por grande parte dos fabricantes do setor. Geralmente empresas multinacionais levam vantagem sobre empresas menores, pois já disponibilizam produtos de baixa emissão desse composto no mercado e fazem a devida divulgação de seu atendimento aos sistemas de certificação ambiental em edificações.

\section{Exigências usuais e novas atividades na construção decorrentes da certificação ambiental}

A partir dos resultados obtidos com a realização do estudo de caso, o Quadro 1 apresenta as novas atividades que foram identificadas como decorrentes da busca de certificação da obra estudada na fase de planejamento e projeto e na fase de produção, envolvendo projetistas, construtores e fornecedores.

\begin{tabular}{|c|c|c|}
\hline & Fase de planejamento e projeto & Fase de produção \\
\hline Projetista & $\begin{array}{l}\text { - soluções arquitetônicas baseadas em } \\
\text { critérios de desempenho } \\
\text { - especificação de materiais, equipamentos e } \\
\text { sistemas levando em conta o desempenho, a } \\
\text { produção regional, a composição, a } \\
\text { reciclabilidade e o descarte final }\end{array}$ & \\
\hline Construtor & & $\begin{array}{l}\text { - plano de qualidade do ar para as fases de } \\
\text { construção e pré-ocupação } \\
\text { - gestão de resíduos da construção } \\
\text { - contratação de fornecedores que atendam às } \\
\text { especificações dos materiais, equipamentos e } \\
\text { sistemas } \\
\text { - comprovação do desempenho de alguns } \\
\text { sistemas diante dos parâmetros da certificação }\end{array}$ \\
\hline Fornecedor & & $\begin{array}{l}\text { - disponibilidade de informações técnicas } \\
\text { sobre os produtos }\end{array}$ \\
\hline
\end{tabular}

Quadro 1 - Atividades exigidas pela certificação 
Quanto às atividades exigidas na fase de planejamento e projeto, é possível concluir que não se trata de atividades realmente novas. Porém, a certificação exigiu um maior esforço no desenvolvimento dos projetos e especialmente na redação do memorial descritivo, tendo como foco questões de desempenho ambiental, as quais muitas vezes são desconsideradas em empreendimentos tradicionais. Essas questões dizem respeito à implantação do prédio (topografia, insolação, ventilação, etc.), ao sistema construtivo (racionalização, materiais envolvidos, desempenhos acústico, térmico, estrutural, lumínico, etc.) e à especificação dos materiais (desempenho, composição, local de origem, reciclabilidade, entre outros quesitos).

Na fase de produção, a realização dos planos de qualidade do ar e a comprovação do desempenho de materiais e sistemas podem ser consideradas como novas atividades a serem desempenhadas pela empresa construtora. Essas práticas não são usuais na construção civil e requerem comprometimento, treinamento e conscientização dos gerentes de obra e operários.

Outra atividade exigida pela certificação é a realização de um sistema de gerenciamento de resíduos da obra, que inclui segregação, reciclagem e descarte apropriados aos resíduos. Essa atividade é perfeitamente alinhada à Resolução 307 do CONAMA (BRASIL, 2002), contudo ainda é pouco praticada nos canteiros de obras.

Além da elaboração desses planos, a construtora teve de solicitar aos fornecedores de materiais documentos que usualmente não são utilizados, tais como ficha técnica, certificações, composição química, grau de reciclabilidade, entre outros. Alguns dos materiais tiveram de ser ensaiados para comprovar o desempenho, o que tornou o processo lento e oneroso, pois o prazo de realização dos ensaios e o custo não foram considerados na programação de compras e no orçamento original da obra. Outra questão a ser considerada é a disponibilidade de materiais na região. Nesta obra os materiais foram especificados por projetistas atuantes em outro estado, e os materiais especificados nem sempre eram encontrados na região da obra.

O comprometimento e o empenho da empresa construtora demonstraram ser cruciais à certificação, o que ficou evidente ao se comparar a atuação das duas empresas contratadas pelo empreendedor. A falta de conhecimento sobre o sistema de certificação da primeira empresa (Construtora A) causou desgaste entre os envolvidos, atrasos na obra, retrabalho, e ainda colocou em risco a certificação da obra. A segunda empresa (Construtora B), por ter maior comprometimento, mostrou maior habilidade na realização da produção da obra, satisfazendo as exigências e requisitos do sistema de certificação.

Por outro lado, o sistema de certificação ambiental exigiu alterações por parte da cadeia fornecedora. Os fornecedores tiveram que disponibilizar informações específicas de seus produtos, usualmente não requeridas, mas que passaram a ser essenciais no processo de certificação. Este pode ser um entrave importante, que envolve não apenas a documentação técnica, mas, principalmente, a capacitação necessária dos profissionais envolvidos no fornecimento e na aquisição de materiais e componentes da indústria da construção no Brasil.

\section{Considerações finais}

A certificação ambiental de prédios pode ser considerada como uma iniciativa em prol da sustentabilidade ambiental na construção, cada vez mais presente no cenário mundial. No Brasil essa prática ainda é incipiente.

$\mathrm{Na}$ pesquisa realizada, a fase de projeto demonstrou ser o norteador principal de todo o processo, exigindo dos projetistas um empenho significativo na introdução de especificações mais detalhadas de materiais e de memoriais mais elaborados bem como conhecimento dos quesitos solicitados pelo método. $\mathrm{Na}$ prática, a implementação e a aplicabilidade dos quesitos exigidos pelo sistema de certificação estudado demonstraram ser ainda mais complexas, pois durante $o$ processo de projeto não havia parâmetros para perceber o grande envolvimento que ocorreria, de todas as partes, durante a fase de produção, incluindo, principalmente, práticas de organização do canteiro, compra de materiais e rigor na fiscalização e na documentação. Os fornecedores também tiveram que se adaptar às exigências do sistema, especialmente disponibilizando mais informações sobre os produtos, uma prática pouco usual na cadeia de fornecimento da construção.

Por fim, a efetiva utilização de sistemas de certificação ambiental de prédios requer novas formas de atuação dos diferentes agentes envolvidos no desenvolvimento dos empreendimentos. Verificou-se a necessidade de uma abordagem sistêmica do processo de gestão desses empreendimentos, envolvendo a requalificação de todos os agentes, desde os operários até a cadeia de fornecedores de materiais e componentes. Não se trata apenas da 
certificação, mas de uma nova visão da atividade da construção civil.

A realização do presente estudo aponta algumas oportunidades de desenvolvimento de trabalhos futuros: a realização de uma análise do desempenho de prédios certificados ao longo da fase de uso; estudos que investiguem o custo decorrente da certificação ambiental de prédios (custos de produção e custos de operação do empreendimento); e o desenvolvimento de ferramentas para o sistema de gestão de empreendimentos que buscam a certificação ambiental.

\section{Referências}

AMERICAN SOCIETY OF HEATING, REFRIGERATING AND AIR CONDITIONING ENGINEERS. Standard 90.1/2004: energy standard for buildings except low-rise residential buildings. Atlanta, 2004.

\section{ASSOCIAÇÃO BRASILEIRA DE NORMAS} TÉCNICAS. NBR 15575: edifícios residenciais de até cinco pavimentos: desempenho. Rio de Janeiro, 2009.

AULICINO, P. Análise de Métodos de Avaliação de Sustentabilidade do Ambiente Construído: o caso dos conjuntos habitacionais. 2008. $144 \mathrm{f}$. Dissertação (Mestrado em Engenharia) Departamento de Engenharia de Construção Civil, Escola Politécnica, Universidade de São Paulo, São Paulo, 2008.

BENINI, H. et al. Analise Simplificada da Sustentabilidade Pós-Ocupação de um Edifício Comercial. São Paulo: Universidade de São Paulo, 2003.

BORGES, C. A. M.; SABBATINI, F. H. O Conceito de Desempenho de Edificações e a sua Importância para o Setor da Construção Civil no Brasil. São Paulo: Departamento de Engenharia de Construção Civil, Escola Politécnica, Universidade de São Paulo, 2008. (Boletim Técnico da Escola Politécnica da USP, $\mathrm{BT} / \mathrm{PCC} / 515)$.

BRASIL. Ministério de Minas e Energia. Balanço Energético Nacional de 2007. Brasília, DF, 2008. Disponível em: <http://www.mme.gov.br>. Acesso em: 20 abr. 2008.

BRASIL. Ministério de Minas e Energia. Eletrobrás. De olho no meio ambiente. Brasília, DF, 2009. Disponível em: <http://www.eletrobras.com/pci/main.asp>. Acesso em: 20 nov. 2009.
BRASIL. Ministério do Meio Ambiente. Conselho Nacional do Meio Ambiente. Resolução no 307, de 05 de Julho de 2002. Estabelece diretrizes, critérios e procedimentos para a gestão dos resíduos da construção civil. Brasília, DF, 2002. Disponível em: <http://www.mma.gov.br/port/ conama/res/res02/res30702.html >. Brasília, DF. Acesso em: 20 mar. 2008.

CAIXA ECONÔMICA FEDERAL. Caixa Lança Selo para Empreendimentos Habitacionais Sustentáveis. Brasília, DF, 2009. Disponível em: <http://www1.caixa.gov.br/imprensa>. Acesso em: 20 nov. 2009.

CANTALAPIEDRA, I. R.; BOSCH, M.; LÓPEZ, F. Involvement of Final Architecture Diploma Projects in the Analysis of the UPC Buildings Energy Performance as a Way of Teaching Practical Sustainability. Journal of Cleaner Production, Oxford, v. 14, n. 9/11, p. 958-62, 2006.

COLE, R. J.; LARSSON, N. GBTool User Manual. Vancouver: GBC, 2002.

COUTO, J. P.; COUTO, A. M. Construction Sites Environment Management: establishing measures to mitigate the noise and waste impact. In: PORTUGAL SB07 SUSTAINABLE CONSTRUCTION, MATERIALS AND PRACTICES, 2007, Lisboa. Challenges of the Industry Form the New Millennium. Amsterdam: IOS Press, 2007.

\section{DEGANI, C. M.; CARDOSO, F. F. A}

Sustentabilidade ao Longo do Ciclo de Vida de Edifícios: a importância da etapa de projeto arquitetônico. São Paulo: Escola Politécnica, Universidade de São Paulo, 2002.

FUNDAÇÃO VANZOLINI. Referencial Técnico de Certificação: edifícios do setor de serviços: Processo AQUA. São Paulo, 2008.

HERNANDES, T. Z.; DUARTE, D. H. LEED-NC como Sistema de Avaliação da Sustentabilidade: questionamentos para uma aplicação local. In: ENCONTRO NACIONAL, 4., ENCONTRO LATINO-AMERICANO SOBRE EDIFICAÇÕES E COMUNIDADES SUSTENTÁVEIS, 2., 2007, Campo Grande. Anais... Porto Alegre: ANTAC, 2007.

HOPFE, C. J. Uncertainty and Sensitivity Analysis in Building Performance Simulation for Decision Support and Design Optimization. 2009. 215 f. Tese (Doutorado em Arquitetura e Urbanismo) - Faculty of Architecture, Building and Planning, Eindhoven University of Technology, Eindhoven, 2009. 
JOHN, V. M. Reciclagem de Resíduos na Construção Civil: contribuição à metodologia de pesquisa e desenvolvimento. 2000. $102 \mathrm{f}$. Tese (Livre Docência) - Escola Politécnica, Universidade de São Paulo, São Paulo, 2000.

PICCOLI, R. Análise das Alterações no Processo de Construção Decorrentes de Método de Certificação de Desempenho Ambiental de Prédios. 2009. 101 f. Dissertação (Mestrado em Engenharia Civil) - Universidade do Vale do Rio dos Sinos, São Leopoldo, 2009.

\section{PIERCE, F. Cimento Ecológico pode Reduzir} Efeito Estufa. [S.l.]: Herbário, 2002. Disponível em: <www.herbario.com.br>. Acesso em: 15 abr. 2008.

PINHEIRO, M. D.; SOARES, L. Contributo para os Mecanismos de Ponderação dos Critérios, no Sistema Lidera, para Avaliação e Gestão Ambiental da Construção Sustentável. In: CONGRESSO NACIONAL DE ENGENHARIA DO AMBIENTE, 8., 2005, Lisboa. Anais... Lisboa: Fórum da Maia, 2005.

PINTO, T. P. Metodologia para a Gestão Diferenciada de Resíduos Sólidos da Construção Urbana. 1999. 189 f. Tese (Doutorado em Engenharia) - Escola Politécnica, Universidade de São Paulo, São Paulo, 1999.
SILVA, V. G. Avaliação da Sustentabilidade de Edifícios de Escritórios Brasileiros: diretrizes e base metodológica. 2003. 210 f. Tese (Doutorado em Engenharia) - Departamento de Engenharia de Construção Civil, Escola Politécnica, Universidade de São Paulo, 2003.

SILVA, V. G. Metodologias de Avaliação de Desempenho Ambiental de Edifícios: estado atual e discussão metodológica. Campinas: UNICAMP, 2007. Projeto Finep 2386/04: Tecnologias para construção habitacional mais sustentável.

U.S. GREEN BUILDING COUNCIL (USGBC). Learn about Green Building. Washington, DC, 2006. Disponível em: <www.usgbc.org>. Acesso em: 15 nov. 2007.

ZIMMERMANN, A. et al. Proposed Framework for Environmental Assessment of Existing Buildings. In: SUSTAINABLE BUILDING, 2002, Oslo. Proceedings... Oslo: iiSBE/CIB/Biggforsk, 2002. 1 CD-ROM. 